\title{
INÍCIO DA DOCÊNCIA NO ENSINO SUPERIOR: ALEGRIA E SOBREVIVÊNCIA NO CURSO DE LETRAS-INGLÊS DA UESPI
}

\author{
BEGINNING OF TEACHING IN HIGHER EDUCATION: JOY AND SURVIVAL IN \\ LANGUAGES MAJOR OF UESPI
}

\begin{abstract}
INICIO DE LA DOCENCIA EN LA ENSEÑANZA SUPERIOR: ALEGRÍA Y SUPERVIVENCIA EN EL CURSO DE LETRAS-INGLÉS DE LA UESPI
\end{abstract}

Renata Cristina Cunha*

\begin{abstract}
Resumo: O início da docência é uma etapa única e fundamental no processo de aprendizagem da profissão. Recorte da tese concluída na Universidade Federal de São Carlos com o objetivo geral de conhecer e analisar as narrativas autobiográficas dos professores do curso de Letras-Inglês da Universidade Estadual do Piauí (UESPI), iniciantes no magistério superior, acerca das experiências formadoras vivenciadas antes do exercício da profissão docente e no início da carreira. No caso específico deste artigo, buscou-se caracterizar e analisar as experiências formadoras dos professores do curso de Letras-Inglês que se tornaram recordações-referência e fontes de aprendizagem profissional no início da carreira no Ensino Superior. Optou-se pela pesquisa autobiográfica de cunho narrativointerpretativo como princípio metodológico-epistemológico, fundamentado em autores como Clandinin e Connelly (2011), Delory-Momberger (2006, 2008, 2009), Chené (2008), Josso (2004, 201), entre outros. Os protagonistas da pesquisa foram três professores, graduados em Letras-Inglês, iniciantes na carreira no Ensino Superior e que, durante a pesquisa, estavam no efetivo exercício da docência na UESPI, campus de Parnaíba (PI). As narrativas orais e escritas foram produzidas durante o ano de 2012, com elaboração dos memoriais de formação, escrita das cartas narrativas e realização dos encontros interativos. As análises e as interpretações das narrativas revelaram que o processo formativo de um deles está diretamente relacionado à sua trajetória de vida, orientado pelas aprendizagens adquiridas e as práticas desenvolvidas ao longo de suas vidas. São as experiências formadoras que cada um traz consigo mesmo, portanto, que singularizam a vida dos três colaboradores da pesquisa.
\end{abstract}

Palavras-chave: Professores de Língua Inglesa. Início na carreira profissional. Ensino Superior. Aprendizagem da docência. Narrativas autobiográficas.

Abstract: The beginning of teaching is a singular phase, fundamental to the profession learning
process. The aim of this paper, part of the thesis concluded at the Federal University of São Carlos/
UFSCar - SP (2014.1) is knowing and analyzing the autobiographical stories of the English professors
who are working for the State University of Piauí (UESPI) in the English major, beginners in Higher
Education about the formative experiences acquired before the teaching work and in the beginning of
their careers. Specifically, the objective of this paper is to characterize and analyze the experiences
lived by the interlocutors of the research when they started their careers of teaching in Higher
Education. An autobiographical research with narrative-interpretative focused in the methodological
and epistemological principle proposed by authors as Clandinin e Connelly (2011), Delory-Momberger

* Professora adjunta II do curso de Letras-Inglês da Universidade Estadual do Piauí. E-mail: renatasandys@hotmail.com 
(2006, 2008, 2009), Chené (2008), Josso (2004, 201), among others was done. The protagonists of this study were three English professors, beginners in Higher Education career who were working at UESPI, campus of Parnaíba, when the research was proposed. The oral and written narratives were produced during the whole year of 2012, with the elaboration of formative memorials, the writings of narrative letters and the accomplishment of interactive meetings. The interlocutors' narratives confirmed that the formative process of each teacher is directly connected to its life trajectory that has guided the gathered learning and the developed practicing throughout their lifetime. What they bring to themselves is the formative experiences and memories-references that set apart the three protagonists of their own history.

Keywords: English professors. Beginning of professional career. Higher Education. Teaching learning process. Autobiographical narratives.

Resumen: El inicio de la docencia es una etapa única y fundamental en el proceso de aprendizaje de la profesión. Recorte de la tesis concluida en la Universidad Federal de São Carlos con el objetivo general de conocer y analizar las narrativas autobiográficas de los profesores del curso de Letras-Inglés de la Universidad Estadual do Piauí (UESPI), iniciantes en el magisterio superior, acerca de las experiencias formadoras vivenciadas antes del ejercicio de la profesión docente y en el inicio de la carrera. En el caso específico de este artículo, se buscó caracterizar y analizar las experiencias formadoras de los profesores del curso de Letras-Inglés que se tornaron recordaciones-referencia y fuentes de aprendizaje profesional en el inicio de la carrera en la Enseñanza Superior. Se optó por la pesquisa autobiográfica de cuño narrativo-interpretativo como principio metodológico-epistemológico, fundamentado en autores como Clandinin e Connelly (2011), Delory-Momberger (2006, 2008, 2009), Chené (2008), Josso (2004, 201), entre otros. Los protagonistas de la pesquisa fueron tres profesores, graduados en Letras-Inglés, iniciantes en la carrera en la Enseñanza Superior y que, durante la pesquisa, estuvieron en el efectivo ejercicio de la docencia en la UESPI, campus de Parnaíba (PI). Las narrativas orales y escritas fueron producidas durante el año de 2012, con elaboración de los memoriales de formación, escrita de las cartas narrativas y realización de los encuentros interactivos. Los análisis y las interpretaciones de las narrativas revelaron que el proceso formativo de uno de ellos está directamente relacionado a su trayectoria de vida, orientado por los aprendizajes adquiridos y las prácticas desarrolladas a lo largo de sus vidas. Son las experiencias formadoras que cada un trae consigo mismo, por tanto, que singularizan la vida de los tres colaboradores de la pesquisa.

Palabras-clave: Profesores de Lengua Inglesa. Inicio en la carrera profesional. Enseñanza Superior. Aprendizaje de la docencia. Narrativas autobiográficas.

\section{Considerações iniciais}

Ao longo do processo de formação docente, os primeiros anos de exercício profissional são basilares para a aprendizagem da docência. É o momento da transição de discente para docente. É o início de um caminho, às vezes nada tranquilo, para tornar-se professor. As experiências vivenciadas nesse período proporcionam aos principiantes sentimentos e emoções que alternam alegrias e descobertas, tristezas e desapontamentos.
Dessas lembranças, emergem não apenas alegrias, encantos e descobertas vivenciadas no período de iniciação à profissão, mas também as dúvidas, as incertezas e os dilemas vivenciados no período, expondo a interface da sobrevivência ao choque da realidade.

Segundo Garcia (1999, p. 39), o professor principiante só consegue sobreviver ao choque da realidade devido à outra face da moeda, a descoberta, definida como “[...] o entusiasmo inicial, a exaltação por estar, 
finalmente, em situação de responsabilidade (ter a sua sala de aula, os seus alunos, o seu programa), por se sentir num determinado corpo profissional”. A descoberta pode, portanto, superar a sobrevivência, potencializada pelo empenho e motivação com a entrada na carreira. Esses dois sentimentos os estimulam não apenas a fazer um bom trabalho, mas também a aplicar o que aprenderam na formação inicial, tentando inovar e utilizar metodologias atuais de sua disciplina.

Nessa perspectiva, como parte da pesquisa de doutorado (CUNHA, 2014), a questão-norteadora deste trabalho é: Que experiências formadoras vivenciadas pelos professores do curso de Letras-Inglês tornaram-se recordações-referência e fontes de aprendizagem docente no início da carreira no Ensino Superior?

Para a realização desta pesquisa autobiográfica de cunho quantitativo, realizada durante o ano de 2012, com memoriais de formação, cartas narrativas e encontros interativos, colaboraram três professores de Língua Inglesa, iniciantes ${ }^{1}$ na carreira no Ensino Superior na UESPI, campus de Parnaíba (PI), aos quais foram atribuídos os seguintes pseudônimos: Coelho Branco, Rainha Vermelha e Rainha Branca, em virtude da proposta da tese sobre Alice no País do Ensino Superior, apresentados a seguir:

O Coelho Branco é natural de ParnaíbaPI, nascido em 1980. Estudou em escolas públicas e privadas da cidade. Concluído o Ensino Médio, passou a trabalhar no comércio. Em 2004, decidiu inscrever-se no vestibular para o curso de Letras-Inglês da UESPI. Durante a graduação foi monitor de quatro disciplinas. Concluída a graduação, fez pós-graduação em Metodologia

\footnotetext{
${ }^{1}$ Apoiando-me em Huberman (1992), considero iniciantes os professores com até três anos de experiência profissional no magistério.
}

do Ensino Superior. Em 2011 ingressou no curso de Letras-Inglês da UESPI como professor substituto, ministrando disciplinas na área de Literatura, além de orientar alunos em seus trabalhos de conclusão de curso.

A Rainha Vermelha nasceu em ParnaíbaPI em 1986. Sempre estudou em escolas particulares. Ao final do $3^{\circ}$ ano, foi aprovada no vestibular para Letras-Inglês, iniciando a graduação em 2004. No ano de 2007, um ano antes da conclusão do curso, matriculei-me no curso de especialização em Língua Inglesa. Em 2011, foi aprovada no processo seletivo como professora substituta do curso de Letras-Inglês da UESPI, ministrando disciplinas relacionadas à Língua Inglesa, além de orientar monografias.

A Rainha Branca nasceu em Parnaíba, Piauí, em 1985. Estudou em escolas públicas e privadas. Em 2004, um ano após a conclusão do Ensino Médio, fui aprovada no curso de Letras Inglês na UESPI. Ainda no último ano da faculdade, inscreveu-se na especialização em Letras-Inglês. No ano de 2011, ingressou como professora substituta do curso de Letras-Inglês da UESPI, ministrando aulas, orientando alunos em monografias e participando de bancas examinadoras de conclusão de curso e de seleção de professores.

Delineados os perfis dos três colaboradores, enfatizamos a opção por um estudo de cunho qualitativo-autobiográfico, enquanto procedimento metodológico, em que se consideram não apenas as narrativas autobiográficas acerca de fatos da vida pessoal e profissional dos professores iniciantes mas também a possibilidade da (re)estruturação das experiências formadoras, contribuindo assim com seu processo de aprendizagem docente. 


\section{Alegrias, encantos e descobertas: 0 início da carreira no Ensino Superior}

Sobre as alegrias no início da profissão, o Coelho Branco escreveu:

Em seus portfólios, para minha surpresa, (realmente não esperava), todos os alunos teceram elogios e disseram ter gostado da maneira como a disciplina foi trabalhada, sempre conectando a teoria com a prática. Um dos alunos me deixou ainda mais surpreso quando relatou que era a melhor disciplina por ele cursada até então. Fiquei com uma sensação de dever cumprido e feliz por ter me saído bem com esta turma. Foi um bom exemplo de que podemos nos sair bem quando nos inspiramos em modelos antes por nós vivenciados e que deram certo. [...] É preciso também amar o que se faz. Eu amo inglês e tudo que está relacionado a ele e amo ensinar. Fico feliz quando alguém se interessa pela língua ou diz que passou a gostar por minha influência. Isso não tem preço. Este tipo de recompensa é muito gratificante e supera algumas dificuldades enfrentadas por nós professores, especialmente quando se está iniciando a carreira. (Memorial do Coelho Branco) Eu acho que eu consegui, busquei várias formas para atingir esse objetivo, alunos que me disseram nunca ter lido um livro em inglês antes e por causa disso tinham lido, ouvi várias vezes eles falando que tinham gostado de tal abordagem, eu gostei disso que você fez professor, vou usar esse tipo de coisa achei legal, você fez uma prova oral, obrigando a gente a ler o livro, sim, mas funcionou, porque eles leram o livro. Eu busquei várias formas para conseguir e de certa forma eu acredito ter contribuído com a formação deles. (Fala do Coelho Branco no sexto encontro).

No fragmento, a “descoberta” no início da carreira é perceptível pelo entusiasmo com que o Coelho Branco registrou suas primeiras experiências profissionais. Ser elogiado pela turma por sua performance profissional, além de tê-lo deixado encantado, fortaleceu seus sentimentos de pertencimento ao grupo, segurança e autoestima (COSTA; OLIVEIRA, 2007). Esses sentimentos são potencializados e construídos ao longo do tempo, fortemente marcados pelo ambiente de trabalho e pela vida do professor.

É possível inferir ainda que, para o colaborador, o sucesso alcançado deveu-se à sua prática docente voltada para a articulação teoria e prática, inspirada em seus exprofessores, e ao seu amor pela Língua Inglesa e pela profissão docente. Na contramão das pesquisas de Cunha e Zanchet (2010) e de Papi e Martins (2009), o depoimento do Coelho Branco indicou que ele não enfrentou uma das dificuldades mais comuns dessa etapa profissional: a articulação teoria e prática. Isso se deu, provavelmente, porque estava ciente de que ambas são interdependentes e interrelacionadas, além de fundamentais para o enfrentamento da realidade docente. O que se justifica também pelo fato de ele ter adotado práticas docentes inspiradas na observação de seus ex-professores (LORTIE, 1975). A adoção dessa prática corrobora os achados de Mariano (2005), ao constatar que é comum os professores iniciantes referenciarem-se em seus antigos professores para realizarem um trabalho bem sucedido, adotando-os como os “mestres-modelo”. É possível observar, portanto, que as aprendizagens adquiridas no período da graduação proporcionaram ao Coelho Branco subsídios para enfrentar a sala de aula, configurando-se como uma importante fonte de alegria e contentamento.

Também se verifica na narrativa que, além da “imitação” de práticas pedagógicas bem sucedidas, a afetividade emergiu como fonte de alegria e encantamento com a profissão: amor pelo inglês e pela profissão docente. Esse depoimento é bastante interessante, pois, conforme esclarecido anteriormente, 
ingressar no Ensino Superior foi uma "sutil” determinação do pai do colaborador. Ressaltase, entretanto, que ele escolheu o curso pelo amor à Língua Inglesa, mas não imaginava seguir a profissão até então. Demonstra, pois, que o professor constitui-se professor, não por vocação ou por herança, como muitos ainda hoje acreditam, mas nas/pelas relações sociais estabelecidas ao longo de sua trajetória pessoal, como no caso do Coelho Branco, durante sua vida acadêmica e no exercício da profissão.

Assumir-se professor universitário transcende as aprendizagens adquiridas com/na formação inicial, implica querer estar e gostar da profissão, bem como se identificar com a carreira universitária. Exige, nas palavras de Oliveira-Formosinho (2010, p. 49), “[...] integração do conhecimento e da paixão”. A exemplo de todas as outras profissões, a docência requer, sim, saberes e conhecimentos específicos, mas demanda também amor e comprometimento, para que o profissional seja bem sucedido na profissão que escolheu seguir, conforme destacado pelo Coelho Branco.

Na parte final do fragmento, o colaborador reportou-se especificamente a uma atividade desenvolvida que, a princípio, não foi bem aceita pelos alunos, mas que depois se mostrou produtiva e foi bastante elogiada. É possível inferir que, ao propor a realização de tal atividade, o professor ouviu muitas reclamações e enfrentou certa resistência da turma. Entretanto, não se curvou diante desse desafio, provavelmente porque estava seguro de seus objetivos, confirmando que se aprende "com as práticas do trabalho, interagindo com os outros, enfrentando situações, resolvendo problemas, refletindo as dificuldades e os êxitos, avaliando e reajustando as formas de ver e de proceder" (CAVACO, 1999, p. 162). Essa situação potencialmente negativa transformou-se em fonte de alegria para o colaborador, graças a seu planejamento e sua organização, contribuindo, assim, para sua autoconfiança e autoestima profissional.

Sobre as alegrias na iniciação à docência, a Rainha Vermelha contou:

Algumas das aulas que mais me vêm à memória facilmente são quando fizemos um relaxamento e a dança medieval em Cultura dos Povos, a entrega de prêmios de Língua Inglesa III, nossa aula prática de Thanksgiving ${ }^{2}$ (com jantar e tudo), a caça ao tesouro, entre outras. [...] Ser homenageada na UESPI, ainda mais ao lado de pessoas tão queridas para mim, foi como uma renovação do meu juramento. Foi como se cenas passassem pelos meus olhos, nas quais eu reafirmava as escolhas que me trouxeram aqui até hoje, escolhas quais que eu repetiria, lógico que consertaria alguns erros cometidos pelo meio do caminho. Reafirmei meu desejo de levar educação a todos e confirmei que meu lugar no mundo é como professora. (Memorial da Rainha Vermelha). No final do semestre, eu fiquei chocada porque os alunos da outra turma me deram um presente e ainda disseram que era o prêmio professora Helena. Professora Helena remete Carrossel, remete àquela professora boa e ainda disseram que, apesar da doença, eu consegui dar as aulas deles graças a Deus, consegui dar aula na outra turma também, [...] Aí a outra turma disse, né, que, eu, eu tenho esse lado apegado, eu me apego muito às pessoas, e eles disseram: - Professora, a senhora, não é uma professora qualquer, a senhora senta, olha, porque que você tá ruim, por quê? O que foi que aconteceu? Você quer ajuda? Tá precisando de ajuda? Tá passando por algum problema? Então vamos pra casa, não adianta ficar aqui e estar com a cabeça no problema porque tu não vai render. Então, por isso disseram que eu

${ }^{2}$ Dia de Ação de Graças, celebrado nos Estados Unidos na quarta quinta-feira do mês de novembro. 
era humana, assim, é uma palavra comum que a gente usa normalmente "humano", mas quando eles disseram isso pra mim, eu senti né, que tinha aquele sentimento, aí quer dizer que me aproximei deles não só pelo profissional, como amiga, né! (Fala da Rainha Vermelha no quinto encontro)

Provavelmente em virtude de sua natureza dinâmica e proativa, a Rainha Vermelha optou por registrar atividades práticas desenvolvidas em sala de aula, revelando o quanto suas características pessoais orientaram e fundamentaram suas práticas docentes, especialmente sua curiosidade, capacidade de renovação e a busca incansável por alternativas para a rotina da vida cotidiana.

Para a realização dessas atividades, as habilidades da colaboradora foram fundamentais, pois implicaram não apenas um planejamento estratégico prévio, mas também o compartilhamento de ideias e discussões em grupo. A incorporação dessas habilidades ao repertório de conhecimentos e saberes docentes indica uma prática pedagógica mais autônoma (GARCIA, 1999), pois foi ela quem tomou as decisões, articulando as demandas das atividades às suas necessidades e às dos alunos, além de ter gerenciado e aprendido com a própria experiência.

Ao contrário do Coelho Branco, que deixou explícitas suas intenções - articular teoria e prátic-, ao planejar e executar determinadas atividades, a Rainha Vermelha apenas descreveu com entusiasmo as atividades realizadas, sem fazer nenhuma menção a essa interface da prática docente. No entanto, a disciplina à qual ela se refere constantemente, Cultura dos Povos, tem uma base bastante teórica, uma vez que trata do percurso histórico do povo britânico e estadunidense, o que permite inferir que, embora ela não tenha mencionado explicitamente (ou de fato não tivesse consciência disso quando escreveu seu memorial), a realização dessas atividades proporcionou aos alunos a articulação teoria e a prática.

Essa articulação, nas palavras de Candau (2002, p. 69), “[...] traz em si a possibilidade do educador desenvolver uma 'práxis’ criadora na medida em que a vinculação entre o pensar e o agir pressupõe a unidade, a inventividade, a irrepetibilidade da prática pedagógica”. Nesse caso, as atividades desenvolvidas pela professora privilegiaram teoria e prática, pois, ao mesmo tempo em que favoreceram a aquisição dos conhecimentos, os alunos tiveram a oportunidade de vivenciá-los na prática, configurando-se, assim, como fonte de alegria e satisfação com a docência universitária.

Na sequência do fragmento, a Rainha Vermelha narrou outros episódios felizes: ser reconhecida como uma professora humana, preocupada e amiga de seus alunos. Zabalza (2004) enfatiza que as relações humanas estabelecidas em sala de aula configuram-se como um forte elemento formador na vida do aluno universitário. As pesquisas de Isaia (2003, 2007) e Maciel e Isaia (2011) revelam que uma das maiores dificuldades dos professores universitários iniciantes é a relação professor-aluno.

Nas palavras de Freire (1996, p. 11), "Não posso ser professor sem me por diante dos alunos, sem revelar com facilidade [...] minha maneira de ser. Não posso escapar da apreciação dos alunos. E a maneira como eles me percebem tem importância capital para o meu desempenho”. É possível constatar, portanto, que a interação com os alunos, mediada pelo diálogo, pela partilha, pela produção de conhecimentos de forma coletiva, com a participação efetiva discente, configurou-se também como fonte de alegria e prazer para a colaboradora, especialmente em virtude 
do problema de saúde enfrentado por ela no período.

A exemplo do Coelho Branco, a Rainha Vermelha também enfatizou seu amor pela profissão, confirmando que, quando o professor realiza seu trabalho com entusiasmo, demonstrando alegria e amor pela profissão (FREIRE, 1996), sente-se profundamente realizado e satisfeito. Por outro lado, quando não gosta da profissão, a relação professor-aluno torna-se desagradável e nada produtiva, comprometendo o processo ensino-aprendizagem.

Sobre as descobertas no início da profissão, a Rainha Branca narrou:

Lembro-me bem, da primeira aula, cheguei muito cedo, montei o retroprojetor, pois ainda nem sabia usar data show direito. $E$ o coração? Palpitava em meu peito, como uma bateria de escola de samba, (rsrsrs) mas eu não podia exteriorizar, tinha que me manter firme, pois não queria passar insegurança para meus alunos. [...] Sai da UESPI, muito feliz aquele dia, pois eu consegui atingir meus objetivos da primeira aula, e o que eu deveria fazer, era tomá-la como exemplo, ao planejar as outras aulas, foi o que eu fiz o semestre inteiro. [...]Fiz uma prova e coloquei a seguinte frase para reflexão no final dela: "The mediocre teacher tells, the good teacher explains, the superior teacher demonstrates, the great teacher inspires". 3 E com letras minúsculas no canto da página uma aluna escreveu: "your're a great teacher". Senti-me tão bem, pois era exatamente o que eu queria passar para meus alunos, não apenas inspirar, mas fazê-los saber que é possível fazer que seus alunos tomem gosto da mesma forma que você. [...] Durante a apresentação dos TCC fiquei muito orgulhosa dos meus alunos, mas

\footnotetext{
${ }^{3} \mathrm{O}$ professor medíocre fala, o bom professor explica, o professor superior demonstra, o grande professor inspira (Minha tradução).

${ }^{4}$ Você é uma grande professora (Minha tradução).
}

principalmente orgulhosa de mim mesma, pois as monografias estavam sendo avaliadas pela comissão julgadora e todas elas receberam nota máxima, sei que nota não diz tudo, mas naquele momento, me diziam que os trabalhos haviam sido completados com êxito. [...] A turma que eu dei aula estava se formando, eles estavam providenciando todas as solenidades para a formatura, e para a minha surpresa fui convidada para ser professora homenageada com unanimidade pela turma. Sei o peso que um professor homenageado tem para a turma, por isso senti-me tão orgulhosa de mim. Parece que com aquele convite eu senti uma resposta para o meu trabalho, foi um grande reconhecimento! [...] Duas datas neste período me marcaram, o dia da própria solenidade de formatura, quando fiz parte da mesa de honra, e que foi um momento ímpar em minha vida, e o dia da aula da saudade. Sempre irei me lembrar, na aula da saudade, quando uma aluna ao homenagear os professores disse que eu "regurgitava conhecimento" (rsrsrs), apesar de engraçado, senti-me lisonjeada com estas palavras, (rsrsrs), [...] Outra turma, da qual eu era professora, estava se formando, já neste ano de 2013, e mais uma vez fui convidada para ser professora homenageada, mas acabei sabendo que esta turma havia colocado o meu nome como o nome da turma, imaginem como eu me senti. Quanta honra! Senti orgulho de mim mesma, e percebi que vale a pena fazer tudo em prol de uma boa educação, e percebo que um bom professor faz a diferença na vida de seus alunos. (Memorial da Rainha Branca). Eu só passei por isso uma vez lá na UESPI no bloco sete, agora os meninos estão no bloco oito, justamente com a disciplina Métodos e técnicas, né! Quando eu cheguei para minha aula, duas professoras já tinham pedido artigos para eles! [...] Aí, eu até fiquei assim, meio... Assim sem saber realmente o que fazer porque eu estava com uma disciplina que eu ia dar todo suporte, né! Aí eles começaram, 
né, nesse dia! Aí teve resistência da turma! "Professora, a gente vai fazer três artigos!". Aí eu, é.... realmente não tem como vocês fazerem três artigos, mas me desculpem as outras professoras, mas essa é a minha disciplina! [...] Eu juro pra vocês que nesse dia eu fiquei orgulhosa dos meus argumentos! Porque eu soube fazer... inclusive eu soube, eu falei assim pra eles "eu vou falar e eu vou perguntar pra vocês se a gente vai fazer o nosso artigo, aí vocês vão me responder". Logicamente depois que eu falei foi engraçado demais! Aí eu falei porque que eles iam fazer! Aí no final vamos fazer? Eles "vamos professora, já diga logo quantas páginas são!”. (Fala da Rainha Branca no sétimo encontro interativo). Eu me sai bem na disciplina Fonética como professora! E ouço até hoje palavras deles "eu adorei a disciplina de Fonética", né! Apesar de todos problemas, apesar de todas as falhas, né! Que a gente sempre tem! Ninguém é $100 \%$ ! Mas o aluno chegar pra você e dizer "professora, aquela disciplina foi maravilhosa, eu amo Fonética”, né! É o caso de uma aluna que está fazendo a monografia dela relacionada a isso! Eu amo Fonética, sabe! Então assim é muito maravilhoso. (Fala da Rainha Branca no primeiro encontro).

Diferentemente dos memoriais de Coelho Branco e Rainha Vermelha, o memorial da Rainha Branca estava repleto de relatos de descobertas da profissão, iniciado com a narrativa detalhada de sua primeira aula na universidade. Alinhando-se aos escritos de Bozu (2009), essa primeira aula da professora na UESPI foi também sua primeira aula como docente universitária. Provavelmente por isso, preparar-se para a aula não foi uma tarefa fácil, gerando sentimentos como insegurança e ansiedade, típicos desse momento profissional. No entanto, assim como para a prova de didática, a colaboradora planejou-se cuidadosamente para ministrá-la, o que lhe garantiu êxito ao final, apesar do natural nervosismo interior. Ter sido bem sucedida nessa ocasião foi, para ela, muito mais que uma fonte de encantamento com a profissão; constituiu-se, na verdade, uma importante base profissional para o enfrentamento das adversidades comuns em sala de aula.

Na sequência da narrativa, é perceptível o quanto ser reconhecida, não apenas como uma professora que inspira seus alunos, mas também competente, dedicada e comprometida, está articulado ao sentimento de descoberta e de encantamento com a docência da Rainha Branca. E esse sentimento é, notadamente, fundamental para os professores iniciantes, pois legitima suas práticas e assegura-lhes segurança para exercer sua prática docente (COSTA; OLIVEIRA, 2007), ou seja, emerge como aprendizagem básica para enfrentar a realidade. Além disso, ser reconhecido pelos alunos potencializa o sentimento de pertencimento profissional ao grupo docente. Para os professores iniciantes, esse sentimento torna-se basilar para a sua performance profissional, como é possível inferir na narrativa da colaboradora.

Além da felicidade por ser reconhecida como fonte inspiradora de seus alunos, a Rainha Branca destacou, na sequência, o quanto se sentiu orgulhosa de si mesma por destacar-se, não apenas como orientadora, mas também como participante ativa de bancas de trabalhos de conclusão de curso. Destaca-se, quanto a isso, que, ao assumir a docência universitária, essas duas tarefas são impelidas ao professor universitário principiante, configurando-se como um grande desafio, sobretudo, pela falta de uma formação adequada para desempenhá-la (CUNHA; ZANCHET, 2010; BOUZADA; KILIMNIK; OLIVEIRA, 2012).

Para enfrentar esses desafios, uma vez mais, a colaboradora recorreu a seu repertório de conhecimentos e saberes, adquirido 
experiencialmente durante sua formação inicial, vez que também produziu sua monografia. O empenho e comprometimento pessoal e profissional da professora possibilitaram-lhe, nessa situação, transformar esses desafios em fonte de alegria, satisfação e orgulho, bem como de muita aprendizagem docente.

Na sequência do fragmento, mais uma experiência de superação, geradora de orgulho e autoconfiança, provavelmente porque foi conquistada pela argumentação fundamentada em um planejamento prévio e cuidadoso. É possível inferir, portanto, que estar seguro de suas decisões e de seu repertório de saberes e conhecimentos é uma poderosa estratégia de sobrevivência (GARCIA, 1999), que colabora não apenas para que o professor universitário principiante enfrente e vença as complexidades da prática docente, mas também para que se sinta mais confiante e orgulhoso de si mesmo, diminuindo o choque com a realidade.

No excerto final de sua narrativa, a Rainha Branca reportou-se a outra experiência de superação, revelando-se orgulhosa e autoconfiante, alinhando-se aos estudos de Zabalza (2004), ao afirmar que ser professor universitário é um exercício complexo que exige a superação de grandes desafios. No caso da colaboradora, esse desafio mostrou-se ainda maior do que o narrado, pois foi na disciplina de Fonética que ela teve uma das suas piores experiências na graduação. Para enfrentar e superar esse desafio, típico da iniciação à docência universitária, a Rainha Branca precisou adotar práticas docentes específicas para reverter essa situação, desenvolvendo sua capacidade de superação, além de fortalecer sua autoconfiança e segurança profissional.

Essa constatação ecoa os estudos de Lortie (1975), confirmando que o reconhecimento dos alunos é a principal fonte de alegrias e encantamento com a profissão dos iniciantes na carreira, pois está atrelada ao prazer e à satisfação com a aprendizagem e sucesso de seus alunos. Os colaboradores realizaram-se não apenas com as atividades de ensino bem sucedidas, mas também com o vínculo afetivo com a profissão e com os alunos.

No entanto, é preciso frisar que determinadas características pessoais contribuem para que as situações difíceis sejam encaradas de forma positiva, como, por exemplo, ter disponibilidade para lidar com o imprevisto, não ter medo de enfrentar desafios, além de ser criativo e determinado (ZABALZA, 2004).

Nas palavras de Garcia (2009, p. 15), “[...] o desenvolvimento profissional procura promover a mudança junto dos professores, para que estes possam crescer enquanto profissionais e também como pessoas”. É sobre a "outra face da moeda”, ou seja, a sobrevivência, que tratam as narrativas do indicador a seguir.

\section{Ser professor universitário iniciante: frustrações, desafios e dilemas}

Das memórias dos professores, emergiram frustrações, dilemas e desafios vivenciados no período, dentre os quais o Coelho Branco relatou:

O processo de distribuição das disciplinas era feito pela própria coordenadora e no meu caso, ela estabeleceu que as disciplinas seriam: "Estrutura e uso da Língua Inglesa" e Literatura Americana I. Ao fazer uma análise de cada disciplina, pensei que não teria problemas com Literatura Americana, pois tive muita afinidade com ela durante a graduação e fiquei apreensivo em relação à outra disciplina, que era relacionada com a Sintaxe da Língua Inglesa, portanto algo um pouco complexo. Era hora então de preparar os materiais. 
[...] Agora no Ensino Superior que a gente se depara a primeira vez com a disciplina, a gente não sabe para que rumo ela vai! Então é muito complicado a gente se planejar para o semestre todo, porque a gente não sabe o que vai acontecer, não sabe pra onde é que vai! E realmente foi muito difícil, é muito difícil você pegar disciplina pela primeira vez e sem saber onde ela vai parar e ir improvisando. (Fala do Coelho Branco no primeiro encontro) [...] O primeiro semestre de minha prática foi bem complicado. De um lado uma disciplina que tinha afinidade (Literatura) e do outro uma disciplina complexa que estava me tirando o sono (Sintaxe). O que qualquer ser humano faria nesta situação? Provavelmente nos dedicaríamos àquela mais complexa e foi isso que fiz. [...] Durante a divisão dos grupos, expliquei superficialmente como eu queria que fosse realizado o seminário. Dentre as exigências, deixei claro que tudo seria apresentado na Língua Inglesa, tanto a parte oral quanto o que fosse apresentado como recurso. Não me ative muito às explicações, pois estava certo de que os alunos já estavam acostumados com esta atividade, afinal já estavam cursando o penúltimo bloco do curso. Posso dizer aqui, francamente, que fiquei muito decepcionado com o que eu presenciei. Com exceção de dois ou três alunos, a maioria deles não demonstrou o mínimo de zelo ou planejamento nas apresentações. Era perceptível a falta de entrosamento entre os membros dos grupos e isso ficou latente quando um deles, formado por seis acadêmicos, apresentou os slides de forma individual, nem ao menos se preocuparam em seguir uma padronização. Outros grupos chegaram a apresentar projeções em português, $o$ que vinha de contramão ao que eu havia solicitado. No final da apresentação de cada grupo, procurava fazer um comentário sobre como o grupo havia se saído e em um destes comentários questionei o fato dos grupos não apresentarem uma padronização na apresentação e a falta de entrosamento entre eles. Fui surpreendido com a resposta de que eles sempre haviam apresentado daquela forma porque eles tinham ocupações durante o dia, o que dificultava os encontros e nenhum professor havia reclamado até então. [...]

Um dos alunos escreveu que eu era um professor razoável, e fez uma comparação com uma grande professora do curso, dizendo que eu não chegava aos pés dela. Foi duro ouvir isso, apesar de ter sido falado por um aluno que faltava muito e que não apresentava um bom desempenho, mas mesmo assim não é fácil ouvir isso. [...] A outra história que me marcou foi de uma aluna, a qual a opinião era muito importante. Ela era uma das melhores, senão a mais empenhada da sala e havia chegado aos meus ouvidos que ela havia comentado que não estava aprendendo nada na minha disciplina. Isso me preocupou, já que quem havia falado isso tinha sido aquela aluna. Então, no dia de receber seu texto com a "self-evaluation" a referida aluna apenas enviou por outro aluno e pediu para avisar que não pôde comparecer por algum motivo. Pedi para que o aluno levasse o material de volta e que ela me procurasse em outro momento e me entregasse pessoalmente. Eu queria muito este encontro, pois a opinião dela era importante para mim. Alguns dias depois ela me procurou na universidade e fomos conversar. No seu texto ela colocou que percebeu meu nervosismo nas primeiras aulas, mas que era aceitável em se tratar de um professor em início de carreira na docência superior e se fosse ela passaria pela mesma situação. Ela seguiu descrevendo minha atuação e afirmou que minhas aulas deixavam a desejar e que não havia aprendido com a minha metodologia. Depois de ler eu agradeci a ela pela sinceridade e que aquelas palavras serviriam de embasamento para a reflexão de minha prática, em busca de uma forma de reverter àquela situação. (Memorial do Coelho Branco)

\footnotetext{
${ }^{5}$ Autoavaliação.
} 
As narrativas do Coelho Branco coadunam-se com os estudos os de Bozu (2009), ao afirmar que o primeiro ano de experiência no Ensino Superior do professor universitário iniciante é problemático e estressante. O colaborador contou, não apenas com riqueza de detalhes, mas também com indícios de reflexão, as situações adversas e angustiantes com as quais se deparou à época, algumas relacionadas às disciplinas ministradas, outras relacionadas às necessidades pedagógicas do processo ensino-aprendizagem e outras, ainda, relacionadas à relação professor-aluno.

Evidentemente, receio e ansiedade acometem a todos no início de uma nova jornada, seja ela de que natureza for, e com o Coelho Branco não foi diferente. No dia da distribuição das disciplinas, o colaborador deparou-se com seu primeiro desafio profissional quando foi incumbido de ministrar duas disciplinas sem receber a devida orientação e acompanhamento, corroborando as pesquisas de Pimenta e Almeida (2009). Ele apenas "recebeu” os dois programas das disciplinas, assumindo o compromisso de cumpri-los, contando apenas consigo mesmo para honrá-lo. Nessa circunstância, vivenciou, simultaneamente, a solidão pedagógica e a insegurança diante da disciplina (ISAIA, 2003).

De acordo com Isaia (2003, p. 373), a solidão pedagógica é “[...] o sentimento de desamparo dos professores frente à ausência de interlocução e de conhecimentos pedagógicos compartilhados para o enfrentamento do ato educativo". O professor recebe apenas a ementa das disciplinas e cabe a ele unicamente planejar, executar e avaliar o seu trabalho, recorrendo, para isso, às suas experiências como aluno da graduação e pós-graduação. Foi esse sentimento que o Coelho Branco vivenciou em virtude da falta de apoio e de orientação, tanto por parte da instituição quanto dos professores mais experientes.
No primeiro semestre como professor universitário, a solidão pedagógica foi agravada pela insegurança diante da disciplina, pois tinha afinidade com apenas uma das duas disciplinas que foi incumbido de ministrar. Se, por um lado, afinar-se com a disciplina Literatura Americana mostrou que, além de conhecer os conteúdos específicos, o colaborador tinha uma preferência pessoal por ela, por outro revelou que não conhecia os conteúdos específicos da Sintaxe, pela qual sequer tinha gosto, razão maior de sua insegurança.

Na prática, de acordo com Isaia e Bolzan (2009), essa insegurança acontece porque a preocupação com o domínio dos conteúdos específicos é uma característica mesmo dos professores experientes. Entretanto, é entre os professores iniciantes que ela é mais acentuada e intensa, especialmente porque o domínio desses conteúdos é reconhecidamente condição sine qua non para a pedagogia universitária.

É perceptível que esse sentimento foi provocado não pela ausência de formação pedagógica para o Ensino Superior (saber-fazer), mas pela falta dos conteúdos específicos da disciplina (saber), corroborando as pesquisas de Isaia (2007), segundo o qual muitas vezes o professor universitário iniciante ensina conteúdos que desconhece. É possível entender, portanto, que o Coelho Branco não enfrentou problemas quanto ao repertório didático-pedagógico porque, em virtude de sua formação inicial (Licenciatura em Letras-Inglês) e continuada (Especialização em Metodologia do Ensino Superior), considerava-se preparado para esse nível de ensino.

A dificuldade em lidar com as necessidades pedagógicas do processo ensino-aprendizagem também emergiu como desencadeadora de sentimentos de angústia, frustração e insatisfação com a Docência Superior. Se, por um lado, mediar o processo 
ensino-aprendizagem é uma tarefa intrínseca à profissão docente, para a qual ele deve ser formado ao longo de sua vida acadêmica e profissional, por outro a prática docente é incerta e imprevisível. Então, por mais que o professor seja ou sinta-se formado, como o Coelho Branco, ele sempre poderá se deparar com situações diante das quais se sentirá inseguro e frustrado, conforme revelado.

Acerca dessa dimensão, Papi e Martins ressaltam:

É no período de iniciação profissional que o professor se defrontará com a realidade que está posta e com contradições que nem sempre estará apto a superar. Seus conhecimentos profissionais são colocados em xeque e a postura que assume pode ir desde uma adaptação e reprodução muitas vezes pouco crítica ao contexto escolar e à prática nele existente, a uma postura inovadora e autônoma, ciente das possibilidades, dos desafios e dos conhecimentos profissionais que sustentam sua ação pedagógica. (PAPI; MARTINS, 2010, p. 44)

Provavelmente por isso, a vivência dessa experiência configurou-se como recordação-referência para ele que, apoiado nos saberes experienciais adquiridos durante a graduação, deduziu que seria desnecessário orientar os alunos sobre uma atividade de ensino e aprendizagem tão recorrente no Ensino Superior, o seminário, especialmente porque o público era composto por alunos veteranos. Para sua surpresa, entretanto, ignorar essa necessidade pedagógica do processo ensino-aprendizagem custou-lhe muita frustração e indignação, além de impactar sua prática docente. Isso talvez tenha acontecido por força da imaturidade profissional do professor que, por ser iniciante, ignorou, ou de fato desconhecia, que como não há um aluno igual ao outro, as experiências vivenciadas por cada um são únicas, mesmo quando realizam as mesmas atividades como, por exemplo, apresentar um seminário.

No final da narrativa, o Coelho Branco revelou duas situações muito difíceis com as quais se deparou quando se submeteu à avaliação de seus alunos. É importante enfatizar que essa decisão partiu do próprio professor, para saber a opinião discente sobre sua prática docente, utilizando-as como subsídios para refletir sobre sua atuação a fim de tornar-se um professor melhor.

A realização dessas duas ações - submeter-se à avaliação dos alunos e refletir sobre essa avaliação - não é comum aos professores universitários iniciantes (CUNHA; ZANCHET, 2010). Elas indicam que, mesmo sendo principiante na carreira, o Coelho Branco parece conhecer uma característica fundamental para o exercício bem-sucedido da profissão, "[...] o cultivo da humildade e da tolerância” (FREIRE, 1996, p. 74), sobretudo ao dialogar com seus alunos. O depoimento do professor alinhou-se aos escritos de Zabalza (2004), ao destacar, entre as muitas habilidades necessárias à docência superior, o gerenciamento das relações interpessoais como fundamental para a prática docente, considerando-se que lidar com pessoas é, simultaneamente, um grande desafio e uma fonte de prazer.

É possível inferir que, se por um lado o colaborador sentiu-se magoado por não ter correspondido às expectativas de dois alunos e chateado por ter entendido que é impossível agradar a todos, por outro se sentiu recompensado com o esforço empreendido e motivado a investir em sua formação para superar aquele obstáculo. Quando um professor se dispõe a refletir sobre suas ações, pensa sobre si mesmo, sobre seus saberes e suas experiências, o que, sem dúvida, servirá de motivação para 
reorganizar suas práticas docentes. Quanto a isso, Isaia enfatiza:

A reflexão sobre a própria prática pode ser entendida como condição de formação profissional. É preciso enfatizar que a prática por si só não gera conhecimento. A reflexão na prática, e sobre ela, vai agregar novas formas de atuação docente, em termos individuais ou coletivos; neste último caso, quando há espaço institucional para tanto. (ISAIA, 2006, p.78)

A reflexão configura-se, portanto, não apenas como um exercício obrigatório para quem é professor, mas como condição sine qua non para o enfrentamento de novos desafios e busca por respostas e soluções.

Acerca dos sentimentos relacionados à sobrevivência no magistério superior, a Rainha Vermelha relatou:

Fui aprovada e então lá íamos nós para a vida de substituto, como já se sabe que não temos muitas escolhas e temos que 'engolir alguns sapos’! Recebi minhas disciplinas que foram Literatura I e Linguística Aplicada à Língua Inglesa, ambas no bloco VI, na época. Ainda bem que a primeira era uma disciplina maravilhosa, que eu adorava, já a segunda, tive probleminhas com ela na graduação, pois foi justamente nessa disciplina que o professor tinha sido injusto comigo e com alguns colegas. O que fazer? Eu não podia passar para os meus alunos o meu descontentamento com a disciplina. Assim resolvi estudar. Ouras, quando não se sabe algo devemos estudar. [...] Então eu não aguentava dar aulas, eu as fiz de uma maneira a desejar e isso estava me matando mais do que a doença! Me sentia decepcionada por não ser a profissional que eu costumava a ser e quase cheguei a ficar com depressão, pois por ser perfeccionista estar numa situação daquelas me levava ao desespero. Pedia desculpas todos os dias por ser uma professora horrível e irresponsável. E assumo que neste semestre eu não contribuí em nada. Fora que alguns alunos não entendiam o quão doente eu estava. [...] Durante a disciplina de Literatura II tive alguns problemas com planejamento. O planejamento foi passado e todos aceitaram. Algum tempo depois eles pediram para que houvesse a alteração de uma atividade e eu perguntei como seria a outra atividade. Conversamos, debatemos e entramos num consenso de uma atividade que substituiria e todos aceitaram perfeitamente a troca. Dias antes da realização da atividade alguns alunos, os mesmos que pediram a primeira troca, queriam trocar a atividade de novo e q eu disse que esta não poderia mais ser modificada, pois envolvia outras pessoas. Outros alunos ficaram firmes e realizaram a atividade enquanto outros desistiram, não foram, inventaram desculpas. A atividade foi realizada com primor pelos alunos que tiveram compromisso e os adolescentes com os quais a atividade foi realizada ficaram imensamente satisfeitos. Quanto aos alunos que não realizaram a atividade ficaram sem a nota, pois os mesmos estavam em sala de aula e votaram pela realização da atividade. Alguns alunos acham que podem obrigar o professor a alterar o planejamento conforme os desejos instantâneos deles e isso não pode acontecer, mas para que o professor tenha argumentos ele precisa se programar. [...] Ao chegar na UESPI, теu entusiasmo era grande, mesmo sabendo que algumas pessoas só fazem inglês por não ter outra escolha e eu pensei que seria capaz de contribuir pelo menos mostrando meu imenso amor pelo inglês. Deparei-me com uma realidade bem adversa, pois geralmente dentro das turmas encontramos uma pequena parcela de pessoas que não querem ser professor, mas nessas turmas atuais é o contrário que acontece, uma pequena parcela quer ser professor, o que nos faz pensar em como será o futuro em nossas salas de aulas, pois ao fim da 
graduação todos eles estarão, digamos, aptos a dar aula. Muitos deles não se esforçam nem para estudar o inglês. Lembrome durante a minha graduação os que ali estavam e permaneciam com os anos se esforçavam cada vez mais para aprender a língua. (Memorial da Rainha Vermelha)

Os depoimentos da Rainha Vermelha corroboram as pesquisas de Papi e Martins (2009) e Zanchet (2011) sobre as dificuldades vivenciadas para a sobrevivência no Ensino Superior. A colaboradora não apenas narrou com detalhes, mas também refletiu sobre as situações desafiadoras relacionadas às disciplinas ministradas, às suas limitações pessoais, aos conflitos do processo ensino-aprendizagem e ao interesse e envolvimento dos alunos com o curso com que se deparou na iniciação à docência.

A exemplo do Coelho Branco, a Rainha Vermelha também se ressentiu do acolhimento ao chegar ao curso e da falta de orientação sobre como conduzir o processo ensino-aprendizagem. É possível inferir que a colaboradora parecia já estar ciente das dificuldades que enfrentaria, não apenas por ser iniciante, mas, sobretudo, por ser contratada.

De acordo com a Lei 8.745 (BRASIL, 1993), esses professores devem ser contratados temporariamente para substituir professores efetivos exonerados, aposentados, afastados para capacitação ou licença. Contudo, a não liberação de verbas para a contratação de professores efetivos é responsável pelo alto número de professores contratados na UESPI, como é o caso dos três colaboradores.

Além das já conhecidas dificuldades enfrentadas pelos iniciantes na carreira, ser contratado ainda acentua essa insegurança, pois, corroborando as pesquisas de Koehler (2006), eles são incumbidos de ministrar qualquer disciplina do curso pelo qual foram contratados, como revelaram o Coelho Branco e a Rainha Vermelha. Isso pode afetar tanto o desempenho de alunos quanto de professores, que, diante do contexto, são obrigados a ministrar aulas sobre assuntos que pouco conhecem ou que até mesmo desconhecem.

As limitações pessoais da Rainha Vermelha relacionadas à fragilidade de sua saúde, também foram listadas como causadoras de angústias e insegurança profissional. O termo mal-estar docente (ZARAGOZA, 1999) tem sido comumente utilizado para caracterizar a situação preocupante vivenciada pelos professores em geral, relacionada aos seus problemas de saúde.

Muito embora a Rainha Vermelha não tenha vinculado o exercício da profissão à fragilidade de sua saúde, ela reconheceu que “foi a gota d’água”, pois estava bastante sobrecarregada profissionalmente à época. Além do mal-estar docente, é perceptível que a colaboradora também foi acometida pelo mal-estar pessoal, pois professor e pessoa são as duas "faces da mesma moeda", o que no período comprometeu sua performance pessoal e profissional.

É possível perceber o quanto o entrelaçamento dos sentimentos de dor, culpa e impotência vivenciados pela Rainha Vermelha "incid[ira]m fundamentalmente sobre a imagem que [ela tinha] de si mesma e de seu trabalho”, pois afetou sua “eficácia docente ao promover um decréscimo da motivação do professor" (ZARAGOZA, 1999, p. 33), conforme revelou. As causas desse mal-estar, ou seja, sua doença, contribuíram negativamente em sua performance profissional, diminuindo sua motivação e empenho, o que aumentou os conflitos pessoais e profissionais. Ainda de acordo com o pesquisador supracitado, para enfrentar esse mal-estar, os professores frequentemente recorrem a licenças médicas, o que não foi o caso da professora, que optou por tentar não deixar que as suas crises 
atrapalhassem suas aulas, faltando quando era necessário.

O senso de responsabilidade e comprometimento com os alunos e com o cumprimento da tarefa assumida foram as razões elencadas pela professora para tomar essa decisão. No entanto, como é perceptível, essa decisão gerou novos conflitos com os alunos, pois muitos foram solidários a sua dor, mas outros não. Esse fato acentuou ainda mais seu mal-estar pessoal e docente.

Assim como o Coelho Branco, a Rainha Vermelha também vivenciou um choque com a realidade devido aos conflitos do processo ensino-aprendizagem. No Ensino Superior, esse processo também deve ser orientado por normas, escolhas pedagógicas, objetivos teóricos e práticos, entre outros, imprescindíveis não apenas para um bom relacionamento entre professor e aluno, mas especialmente para a aprendizagem dos conteúdos (MASETTO, 2003). Por isso, é muito importante que o professor estabeleça um "contrato" com seus alunos definindo normas acerca do comportamento esperado de ambas as partes, assim como fez a colaboradora.

Ao ser questionada sobre o estabelecimento desse contrato, ela respondeu que aprendeu com uma de suas ex-professoras que sempre apresentava o plano de trabalho no primeiro dia de aula, indicando uma aprendizagem adquirida quando acadêmica. Assim como o Coelho Branco, a colaboradora imaginou que não teria problemas com o processo ensino-aprendizagem, pois as atividades haviam sido previamente combinadas e "contratadas". No entanto, não foi isso que aconteceu.

O depoimento indicou que a Rainha Vermelha adotou, a princípio, uma prática mais aberta e flexível, aceitando negociar a atividade ao ser questionada pelos alunos, tentando manter uma relação empática, exercitando sua capacidade de ouvir, refletir e discutir o processo ensino-aprendizagem, habilidade basilar do professor universitário (ZABALZA, 2004). Contudo, uma vez mais, foi surpreendida com o comportamento de alguns alunos que solicitaram uma nova atividade para substituir a anterior. Mas, ao contrário da postura anterior, dessa vez manteve-se firme e, fundamentada em seu bom senso, pois outros alunos já haviam realizado a tarefa com êxito, não atendeu à solicitação.

Essa tomada de decisão da professora ocasionou dois conflitos específicos: a indisciplina dos alunos ao se negarem a cumprir a atividade proposta e, consequentemente, o baixo aproveitamento desses mesmos alunos em virtude do não cumprimento dessa tarefa. Essas duas "faces da mesma moeda" configuraram-se como grandes obstáculos para o trabalho docente da Rainha Vermelha, acentuando sua angústia e insegurança.

No fragmento final, mais uma experiência geradora de sentimentos negativos em relação à profissão. Dessa vez, específica dos professores de inglês: acadêmicos do curso que demonstraram não se interessar pela docência e outros que sequer se interessavam em aprender a língua. A literatura de formação de professores de inglês (GIMENEZ, 2005; PAIVA, 2005) tem discutido amplamente essa temática, apontando as preocupações, assim como a Rainha Vermelha, com a formação dos atuais/futuros professores de inglês.

Silva e Margonari (2003, 2004) identificam três tipos de acadêmicos do curso de Letras-Inglês: 1) aquele que, desde o início, identifica-se com o curso e quer ser professor de Inglês; 2) aquele que, apesar de se identificar com o curso, não se vê como professor e 3) aquele que não se interessa por aprender a língua nem se vê como professor. Infelizmente, de acordo com a colaboradora, a maioria de seus alunos à época pertencia ao 
terceiro grupo, constatação que a entristeceu e preocupou.

De acordo com os pesquisadores, isso acontece porque o alunado tem enfrentado dificuldades para assumir-se tanto como aluno quanto como professor de inglês durante a formação nos cursos de Letras-Inglês. Destacase a necessidade de dominar a língua, vez que, conforme previamente discutido, embora o foco do curso seja a formação de professores, para a grande maioria dos licenciandos, ser professor não é a primeira opção.

Sobre os seus sentimentos de sobrevivência, a Rainha Branca contou:

Após a conclusão e o resultado do teste, tive uma reunião com a coordenadora do curso para saber quais as disciplinas que eu iria ministrar. E eis que surge o pesadelo chamado "Phonetics and Phonology". No mesmo instante, me recordei das minhas aulas de fonética da graduação, e o quanto eu não tinha aprendido, eu só tinha sentia medo e angústia quando eu me lembrava desta disciplina. Tínhamos passado por ela não havíamos aprendido o que era a fonética. Pois bem, falando ainda sobre a disciplina, a qual me traumatizou, eu não tinha a menor ideia por onde começar, a quem recorrer. [...] Eu não queria entrar em uma sala de aula e me ver diante dos meus alunos e não saber o que dizer e fazer. Como eu iria ministrar uma aula, se eu não tinha nenhuma bagagem para tal? [...] Pois bem, falei muito de Fonética, mas minha primeira aula na universidade foi em uma turma de sétimo período, a disciplina foi de Métodos e Técnicas de Pesquisa que recebi com Fonética, a qual também era uma disciplina que eu não dominava, apesar de tê-la estudado com êxito, não era uma disciplina que eu estava apta para ministrar, mas era a disciplina que havia sobrado para mim, (rsrsrs), pois fui a última professora a entrar no quadro naquele

${ }^{6}$ Fonética e Fonologia. semestre. [...] Meus maiores problemas baseavam-se na falta de experiência que eu não tinha diante de alguns assuntos. Por exemplo, eu sempre combinei todas as atividades do semestre logo no primeiro dia de aula, portanto, marquei um seminário para acontecer quase no fim do semestre, ou seja, elas foram marcadas com muita antecedência para justamente os alunos não poderem se reclamar de falta de tempo tampouco de programação. No referido seminário, uma das alunas não compareceu. Não ligou para comunicar sua ausência, não avisou para seus amigos de sala, tampouco para seus companheiros do grupo do seminário. Eu entrei em um dilema, o que eu deveria fazer? Dar nota zero? O que aconteceu com ela, para ela perder o seminário? Inclusive este seminário era para dar a nota final do semestre. [...] Depois de muitos desafios, outros aconteceram. O primeiro pensamento que me veio foi de que eu não estava preparada para tal desafio, uma vez que eu não havia sido capacitada, nem na universidade e nem em nenhum outro lugar para realizar tal tarefa. Eu sabia que ia ser árdua esta tarefa, e estava pronta para este desafio. No decorrer deste período, tentei dar o máximo de mim, mas foi muito difícil orientar, pois eu não tinha experiência nenhuma como orientadora, só tinhas as observações que eu fazia dos meus professores. À medida que os dias iam passando, eu ia ficando mais nervosa, pois a conclusão dos TCC iam se concretizando, e eu sempre me perguntava se as monografias faziam sentido (sempre rio com esta observação e que meus alunos não saibam disso!), ou seja se realmente tinham um começo, meio e fim, se o objetivo do TCC havia sido alcançado. (Memorial da Rainha Branca)

Os escritos da Rainha Branca corroboraram as pesquisas de Maciel e Isaia (2011) e Isaia e Bolzan (2004) entre outras, sobre os desafios e dificuldades vivenciadas para sobreviver no Ensino Superior. A colaboradora 
registrou suas reflexões sobre essas situações desafiadoras e dilemáticas com as quais se deparou no início da carreira universitária, relacionadas às disciplinas ministradas, às relações professor e aluno no processo de ensino-aprendizagem e, por fim, às exigências institucionais da docência universitária.

Em virtude do perfil dos colaboradores, é possível confirmar os resultados de Cunha, Brito e Cicillini (2006) e Castanho (2007), entre outros, ao afirmarem que dificilmente, durante as reuniões para enquadramento docente, os iniciantes são ouvidos e que, em virtude disso, são "forçados" a assumir as disciplinas preteridas pelos professores veteranos, o que acentuada ainda mais a insegurança e o receio dos iniciantes, conforme relataram os colaboradores. Essas condições de trabalho oferecidas pelas instituições aos iniciantes na carreira são denunciadas por Lelis (2012), que as caracteriza como perversas.

Da mesma forma do Coelho Branco e da Rainha Vermelha, em seu primeiro semestre na UESPI, a Rainha Branca também assumiu duas disciplinas diferentes. No entanto, diferentemente dos dois, eram duas disciplinas com as quais não possuía nenhuma afinidade, ou seja, além de não gostar, sabia que não tinha conhecimentos dos conteúdos suficientemente para ministrá-las. Havia ainda um sério agravante: com uma das disciplinas teve uma experiência traumática na graduação.

Assim como seus colegas, a colaboradora não se esquivou do desafio, encarando-o com determinação e comprometimento, características fundamentais para seu êxito profissional. Antes de ministrar as aulas, voltou-se a aprender os conteúdos e preparar-se adequadamente para ministrá-los, pois queria mostrar-se segura e sapiente diante de seus alunos. Zabalza (2004) afirma que, embora não seja o suficiente, conhecer bem a disciplina é importante para o sucesso da ação docente. Por isso, conforme previamente discutido, dominar esses conteúdos é considerado o atributo primordial para exercer a docência no Ensino Superior, o que explica a insegurança e medo da Rainha Branca quando assumiu suas turmas.

Também a exemplo do Coelho Branco e da Rainha Vermelha, a Rainha Branca enfrentou dificuldades para lidar com as especificidades do processo ensino-aprendizagem, causadas por uma aluna em especial. As palavras da colaboradora revelaram indignação, desapontamento e frustração com a ausência dessa aluna no dia da apresentação de uma atividade avaliativa. Revelaram também um típico dilema docente, especialmente entre os professores iniciantes (MOROSINI, 2000): o que fazer diante de uma situação como essa? É essa incerteza sobre o que fazer que gera sentimentos negativos nos principiantes, como confirmou a Rainha Branca. Para superar esse desafio, uma vez mais, recorreu às orientações de professora-espelho.

No fragmento final de sua narrativa, a colaboradora revelou outro embate, ao deparar-se com uma exigência institucional bastante comum nas faculdades e universidades: orientar trabalhos de conclusão de curso. Essa incumbência revela-se, por vezes, geradora de insegurança entre os professores universitários iniciantes, como destacam Vieira, Guebert e Filipak (2012). Apesar da surpresa ao ser convidada, pois ela não se achava capacitada para exercer tal tarefa por ser principiante e também por não ter experiência, uma vez mais a Rainha Branca demonstrou não temer desafios e, apesar do medo de falhar, aceitou o convite.

Retomando as narrativas da colaboradora sobre as alegrias com a descoberta da profissão, fica claro o quanto o enfrentamento desse choque inicial foi basilar para a 
sua autoestima e autoconfiança, pois o que começou como uma situação desafiadora tornou-se uma preciosa fonte de aquisição e materialização de saberes e conhecimentos profissionais, sobretudo os experienciais (GARCIA, 1999; TARDIF, 2002). Nesse sentido, além das aprendizagens experienciais, ou seja, aquelas originadas nas vivências dos professores, foi também pelo seu modo de perceber, interpretar e materializar sua prática que a professora consolidou seu percurso formativo, desenvolvendo-se profissionalmente.

Provavelmente devido à sua condição, iniciantes na carreira universitária, os colaboradores sobreviveram ao período de iniciação à docência, a despeito das dificuldades, dos conflitos, dos dilemas e das preocupações que enfrentaram. Esses sentimentos estão relacionados às várias interfaces do trabalho docente, específicas desse nível de ensino: as dimensões do processo ensino-aprendizagem, as demandas dos alunos, a falta de apoio e/ ou orientação por parte da instituição e dos professores mais experientes e, sobretudo, a falta de experiência profissional.

Ressalta-se que, dentre as dificuldades elencadas pelos colaboradores, algumas não são exclusivas dos iniciantes na carreira, como os conflitos com os alunos e a assunção de disciplinas sem a formação devida. Essas adversidades também são vivenciadas pelo professorado mais experiente de instituições públicas e privadas (MASETTO, 2002; GATTI, 2010). No entanto, apesar de não serem “privilégio” apenas de quem está no início da profissão, é possível deduzir que elas tendem a se acentuar quando vivenciadas pelos iniciantes, como narraram os colaboradores.

As análises das narrativas indicam que a gênese de algumas das dificuldades e desafios vivenciados pelos colaboradores está nas lacunas formativas deixadas pela formação inicial, considerada por Paiva (2003, 2005) como fragmentada e precária porque negligencia tanto o conhecimento sólido da Língua Inglesa quanto a formação para a docência. Isso contribui sobremaneira para tornar a inserção profissional mais problemática, uma vez que os alunos-professores não têm sido formados para lidar com a complexidade da profissão docente.

É possível constatar, portanto, que o choque com a realidade, sentido e relatado pelos colaboradores ao ingressarem no magistério superior, aconteceu também em virtude das expectativas que tinham sobre os alunos com os quais iriam trabalhar, alinhando-se aos escritos de Tardif e Raymond (2000) e Zabalza (2004) sobre o choque entre o ideal, expectativas dos professores, e o real, o verdadeiro comportamento diante dos alunos.

Frente às dificuldades, aos desafios e dilemas dessa primeira fase do exercício da profissão, o acompanhamento pedagógico do principiante por um professor mais experiente, especialmente no primeiro ano da docência tem sido amplamente defendido pela literatura internacional e nacional, a saber, Bozu (2009), Garcia (2009, 2011), Papi e Martins (2010) e outros, como essencial para a permanência do iniciante na carreira, especialmente pela segurança, apoio e orientação que isso pode proporcionar ao professor principiante.

Apesar da ampla divulgação de pesquisas acerca da grande relevância desse acompanhamento para amenizar o choque com a realidade, os colaboradores confirmaram não ter recebido qualquer orientação ou acompanhamento pedagógico para auxiliá-los nesse momento de sua trajetória profissional, tornando-se, assim, os únicos responsáveis por sua sobrevivência na profissão. 


\section{Considerações finais}

O ser e o fazer-se professor universitário foi confirmado como uma atividade complexa pelos colaboradores, cuja reconstituição da trajetória formativa remeteu a experiências marcantes vivenciadas ao ingressarem na docência superior. Esses movimentos constitutivos emergiram como um processo dinâmico, interpessoal, não-linear e não-intencional nesse período. Além dessa aprendizagem adquirida pela observação, para o exercício profissional da docência, as experiências vivenciadas nas atividades de ensino durante a formação inicial configuraram-se como amplamente formativas para o processo de aprender a ensinar dos colaboradores, confirmando o destaque dessa importante etapa para sua formação e desenvolvimento profissional.

Em linhas gerais, as narrativas dos colaboradores revelaram que as experiências vivenciadas na sala de aula como professores universitários iniciantes foram momentos que facilitaram a iniciação na profissão e ajudaram a suavizar as dificuldades com as quais se depararam nesse período, sobretudo aquelas vivenciadas com os alunos, fonte principal de satisfação pessoal e profissional. Nesse sentido, além das aprendizagens experienciais, ou seja, aquelas originadas nas vivências dos professores, foi também pelo seu modo de perceber, interpretar e materializar sua prática que os colaboradores consolidaram seus percursos formativos, desenvolvendo-se profissionalmente.

Além do reconhecimento de seus alunos e da sensação de dever plenamente cumprido, as narrativas dos colaboradores revelaram outros sentimentos de entusiasmo e euforia no início da profissão, decorrentes da autonomia docente e do sentimento de pertencimento a um grupo profissional. A vontade de acertar e de ser reconhecido, aliada ao compromisso com os alunos, levam os iniciantes a resistir às dificuldades. O entrelaçamento desses sentimentos materializou-se na descoberta da profissão, auxiliando os colaboradores na busca por alternativas de resolução e superação dos problemas. É possível constatar, portanto, que essas características foram os alicerces para as decisões tomadas pelos três colaboradores.

Acerca dos processos formativos vivenciados na/pela prática profissional na assunção da profissão, os depoimentos dos colaboradores revelaram sentimentos de angústia, de euforia, de ansiedade, de incerteza, alternando momentos relacionados à sobrevivência e à descoberta da profissão. Destacaram a solidão pedagógica e a insegurança diante das disciplinas a serem ministradas, além das necessidades pedagógicas do processo ensino-aprendizagem, o distanciamento entre os alunos ideais e os reais e a busca constante por técnicas e estratégias de ensino atraentes como aspectos dificultadores da prática docente nessa etapa profissional.

Também evidenciaram a afetividade entre professor e aluno, a satisfação com a aprendizagem discente, o status social da docência universitária, bem como o compromisso com a formação de futuros professores de Língua Inglesa, o entusiasmo com o reconhecimento e valorização de suas ações profissionais como responsáveis pelas alegrias e encantamento com a docência. Refletiram, ainda, sobre a aquisição, materialização e produção dos saberes profissionais como fundamentais para sua prática docente. E mais: assumiram-se como aprendizes, isto é, como profissionais em constante processo de formação. Nessa perspectiva, reconheceram que, para sua atuação profissional, espelharam-se e inspiraram-se nas formas de saber, saber-ser e saber-fazer de seus antigos professores considerados como modelos a serem seguidos (ou não). 
A iniciação à docência é marcada, portanto, por sentimentos conflitantes e, ao mesmo tempo, determinantes para a permanência ou não do professor na profissão, bem como para o tipo de docente que ele será, que pode ser vivenciada pelos iniciantes como fácil ou difícil. Muito embora em seus depoimentos os colaboradores tenham elencado as muitas dificuldades com as quais lidaram nesse período, os três foram unânimes em afirmar que essas dificuldades foram transformadas em desafios a serem enfrentados e vencidos, o que demonstra não apenas coragem e disposição, mas também determinação e comprometimento com a profissão.

\section{Referências}

BOUZADA, V. C. P. C.; KILIMNIK, Z. M.; OLIVEIRA, L. C. V. de. Professor iniciante: desafios e competências da carreira docente de nível superior e inserção no mercado de trabalho. ReCaPe - Revista de Carreiras e Pessoas, São Paulo, v. 02, n. 01, jan. /fev. / mar. /abr. 2012.

BOZU, Z. El profesorado universitario novel y su proceso de inducción profesional. Magis: Revista Internacional de Investigación en Educación, n. 2, p. 317328, Bogotá, Colombia, ene./jun. 2009.

BRASIL. Lei $\mathbf{n}^{\mathbf{0}}$. 8745, de 09 de dezembro de 1993.

CANDAU, V. M. A relação entre teoria e prática na formação do educador. In: (Org.). Rumo a uma nova didática. Petrópolis: Vozes, 2002.

CASTANHO, M. E. Pesquisa em pedagogia universitária In: CUNHA, M. I. (Org.). Reflexões e práticas em pedagogia universitária. Campinas, SP: Papirus, 2007.
CAVACO, M. H. Ofício de professor: o tempo e as mudanças. In: NÓVOA, A. (Org.). Profissão professor. Portugal: Porto, 1999. p. 84-107.

CHENÉ, A. A narrativa de formação e a formação de formadores. In: NÓVOA, A.; FINGER (Org.). O método (auto) biográfico e a formação. Lisboa: Ministério da Saúde, 2008. p. 87-97.

CLANDININ, D. J.; CONNELLY F. M. A pesquisa narrativa: experiência e história em pesquisa qualitativa. Uberlândia: EDUFU, 2011.

COSTA, J. S.; OLIVEIRA, R. M. M. A. A iniciação na docência: analisando experiências de alunos professores das licenciaturas. Olhar de professor, Ponta Grossa, v. 10, n. 2, p. 23-46, 2007.

CUNHA, R. C. da. Narrativas autobiográficas de professores iniciantes no Ensino Superior: trajetórias formativas de docentes do curso de Letras-Inglês. 2014. 304 f. Tese (Doutorado em Educação) Universidade Federal de São Carlos, São Carlos, 2014.

CUNHA, M. I.; ZANCHET, B. M. B. A. A problemática dos professores iniciantes: tendência e prática investigativa no espaço universitário. Educação, Porto Alegre, v. 33, n. 3, p. 189-197, set./dez. 2010.

CUNHA, A. M. de O.; BRITO, T. T. R.; CICILLINI, G. A. Dormi aluno (a) acordei professor: interfaces da formação para o exercício do ensino superior. In: SILVA, J dos R. S.; OLIVEIRA, J. F. de O.; MANCEBO, D. (Org.). Reforma universitária: dimensões e perspectivas. São Paulo: Alínea e Átomo, 2006. p. 146-161.

DELORY-MOMBERGER, C. Recit de soi et formation. Revista@mbienteeducação, São Paulo, v. 2, n. 2, p. 9-21, ago./dez. 2009. 
- Biografia, corpo, espaço. In: PASSEGGI, M. da C. (Org.). Tendências da pesquisa (auto) biográfica. Natal-RN: EDUFRN; São Paulo: Paulus, 2008. p. 2953.

Formação e socialização: os ateliês biográficos do projeto. Educação e Pesquisa, São Paulo, v. 32, n. 2, p. 359-371, maio/ago. 2006.

FREIRE, P. Pedagogia da autonomia: saberes necessários à prática educativa. São Paulo: Paz e Terra, 1996.

GARCIA, C. M. El profesorado principiante: inserción a la docencia. Barcelona, Octaedro, 2009.

Formação de professores para uma mudança educativa. Porto: Porto, 1999.

GATTI, B. A. et al. Formação de professores no Brasil: características e problemas. Educação \& Sociedade, Campinas, v. 31, n. 113, p. 1355-1379, out.- dez. 2010.

GIMENEZ, T. Desafios contemporâneos na formação de professores de línguas: contribuições da lingüística aplicada. In: M. M. FREIRE, M. H. V; ABRAHÃO, A. M. F. BARCELOS. (Orgs.). Lingüística aplicada e contemporaneidade. Campinas: Pontes, 2005. p. 183-201.

HUBERMAN, M. O ciclo de vida profissional dos professores. In: NÓVOA, A. (Org.). Vidas de professores. Portugal: Porto, 1992. p. 31-62.

ISAIA, S. Aprendizagem docente como articuladora da formação e do desenvolvimento profissional dos professores da Educação Superior. In: ENGERS, M. E.; MOROSINI, M. (Orgs.). Pedagogia universitária e aprendizagem. Porto Alegre: EDIPUCRS, 2007. p. 153-165.
Formação do professor de ensino superior: tramas na tessitura. In: MOROSINI, M. (Org.). Enciclopédia de pedagogia universitária. V. 1. Porto Alegre: FAPERGS/RIES, 2003, p. 241-251.

ISAIA, S.; BOLZAN, D. P. V. Elementos constitutivos do processo formativo de professores que atuam em licenciaturas. X Seminário Nacional Univérsitas. Porto Alegre: PUCRS/UFRGS, 2009.

JOSSO, M. C. Caminhar para si. Tradução Albino Pozzer. Porto Alegre: EDIPUCRS, 2010.

. Experiência de vida e formação. São Paulo: Cortez, 2004.

KOEHLER, S. E. A trajetória institucional/ docente do professor substituto da UFSM. 2006. 160 f. Dissertação (Mestrado em Educação) - Universidade Federal de Santa Maria, Santa Maria, 2006.

LELIS, I. O trabalho docente na escola de massa: desafios e perspectivas. Sociologias, Porto Alegre, ano 14, n. 29, jan./abr., p. 152174, 2012.

LORTIE, D. School-teacher: a sociological study. Chicago: University of Chicago Press, 1975.

MACIEL, A. M. R.; ISAIA, S. M. de A. Comunidades de práticas pedagógicas universitárias em ação: construindo a aprendizagem docente. Imagens da Educação, v. 1, p. 37-47, 2011.

MARIANO, A. L. S. A construção do início da docência: um olhar a partir das produções da ANPED e do ENDIPE. 2005. 147 f. Dissertação (Mestrado em Educação). São Carlos: Universidade Federal de São Carlos, 2005. 
MASETTO, M. T. Competência pedagógica dos professores universitários. São Paulo: Summus, 2003.

- Docência na universidade.

Campinas, SP: Papirus, 2002.

MOROSINI, M. C. Docência universitária e os desafios da realidade nacional. In:

(Org.) Professor do Ensino Superior: identidade, docência e formação. Brasília: Plano, 2000. p. 94-118.

OLIVEIRA-FORMOSINHO, J. Formação, desempenho e avaliação de professores. Mangualde: Edições Pedagogo, 2010.

PAIVA, V. L. M. O novo perfil dos cursos de Licenciatura em Letras. In: TOMICH, A. L. et al. (Orgs.). A interculturalidade no ensino de inglês. Florianópolis: UFSC, 2005. p. 345-363.

A LDB e a legislação vigente sobre o ensino e a formação de professor de Língua Inglesa. In: STEVENS, C. M. T; CUNHA, M. J. Caminhos e colheitas: ensino e pesquisa na área de inglês no Brasil. Brasília: UNB, 2003. p. 53- 84.

PAPI, S. O. G.; MARTINS, P. L. O. Professor iniciante. In: OLIVEIRA, D. A.; DUARTE, A. M. C.; VIEIRA, L. M. F. Dicionário: trabalho, profissão e condição docente. Belo Horizonte: UFMG/Faculdade de Educação, 2010. CD-ROM.

Professores iniciantes: as pesquisas e suas bases teórico-metodológicas. Linhas Críticas, Brasília, v. 5, n. 29, p. 251-269, jul./dez. 2009.

PIMENTA, S, G.; ALMEIDA, M. I. de (Orgs.). Pedagogia universitária. São Paulo: EDUSP, 2009.

SILVA, A.; MARGONARI, D. M. O que revelam os relatórios de estágio supervisionado sobre a formação de professores de língua inglesa. Contexturas: ensino crítico de língua inglesa, São Paulo, n. 7, p. 39-53, 2003/2004.

\section{TARDIF, M. Saberes docentes e formação profissional. Petrópolis: Vozes, 2002.}

TARDIF, M.; RAYMOND, M. O trabalho docente, a pedagogia e o ensino: interações humanas, tecnologia e dilemas. Cadernos de Educação, Faculdade de Educação da Universidade Federal de Pelotas, ano 10, n. 16, p. 7-14, jan./jun. 2001.

VIEIRA, A. M. D. P.; GUEBERT, M. C. C.; FILIPAK, S. T. A formação continuada dos professores da educação superior. Olhar de professor, Ponta Grossa, n. 15, v. 2, p. 337351, 2012.

ZABALZA, M. A. O ensino universitário: seu cenário e seus protagonistas. Porto Alegre: Artmed, 2004.

ZANCHET, B. M. B. A. Ensino e pesquisa: desafios e possibilidades para docentes universitários iniciantes. Inter-Ação, Goiânia, v. 36, n. 2, p. 577-590, jul./dez. 2011.

ZARAGOZA, J. M. E. O mal estar docente: a-sala-de-aula e a saúde dos professores. Bauru, SP: EDUSC, 1999. 